\title{
Effects of butter, some margarines and arachis oil in purified diets on serum lipids and atherosclerosis in rabbits
}

\author{
By J. P. FUNCH, B. KROGH AND H. DAM \\ Department of Biochemistry and Nutrition, Polytechnic Institute, Copenhagen \\ (Received 3 December I959-Revised I February 1960)
}

Although many investigators have studied the development of hypercholesterolaemia and atherosclerosis in rabbits by adding cholesterol to commercial rabbit feeds, there are relatively few studies of the influence of dietary fat on serum-cholesterol concentrations and atherosclerosis in rabbits fed on purified diets without added cholesterol.

The purpose of the experiment reported here was to study the effect of arachis oil, butter or fat mixtures made into margarines on serum cholesterol and lipoproteins and on the development of atheromatous lesions in rabbits fed on purified diets without added cholesterol.

\section{EXPERIMENTAL}

Male rabbits, 6 months old and weighing between 2 and $3 \mathrm{~kg}$, purchased from a local dealer, were distributed over five groups, nine animals in each group. They were caged individually on raised wire screens. Most of the rabbits (thirty-six) were albinos of the so-called country breed, and the rest (nine) were mongrels with a mostly black fur. The mongrels were distributed over the groups. To accustom the rabbits to the purified diet, it was gradually substituted for a pulverized commercial feed during the 2 weeks before the beginning of the experiment. During this period of conditioning the purified diet contained $20 \%$ by weight of arachis oil. Food and water were given ad lib., and the food consumption was estimated throughout the experiment, which lasted 42 weeks. The dietary fats were arachis oil, butter and three margarines $\left(M_{1}, M_{2}\right.$ and $M_{3}$ ) made for the purpose. The amount of water and salt present in the butter and the margarines was allowed for, so that the fat contents of all the diets were $20 \%$ by weight, which provided $39 \%$ of the total calories. The natures of the dietary fats are shown in Table $I$, and the compositions of the diets in Table 2 . The fats were stored at $-20^{\circ}$. For practical reasons, new batches of all the fats were provided after 26 weeks. The rabbits were weighed weekly. At the outset of the experiment and every 5 weeks afterwards the rabbits were bled from the marginal ear veins. Food cups were removed at $5 \mathrm{a}$ a.m. before collection of blood at noon. Serum was separated by centrifugation, and cholesterol was determined, in duplicate portions of 0.05 or $0.02 \mathrm{ml}$, by the method of Herrmann (I957). After an experimental period of 20 weeks lipoproteins were determined in the serum by paper electrophoresis as decribed by Swahn (I953). At the end of 42 weeks' feeding the rabbits were anaesthetized with ether, blood was withdrawn from the heart and they were then killed. Food cups were 
removed at 4 p.m. on the day before autopsy. The opened unstained aorta and pulmonary artery, from origin to ramification, with their valves were examined macroscopically. For grading purposes the aorta was divided into the thoracic and abdominal parts, and the severity of atherosclerosis was graded on a scale of 0 to 4 . Grades I, 2, 3 and 4 indicated, respectively, an involvement of approximately 10, 20, 40 and $80 \%$ of the intimal surface area (McMillan, Horlick \& Duff, 1955). However,

\section{Table $\mathrm{r}$. Percentage composition and constitution of dietary fats}

Dietary fat $\overbrace{M_{1}}^{M_{2}} M_{3} \quad$ Butter $\begin{gathered}\text { Arachis } \\ \text { oil }\end{gathered}$

\begin{tabular}{|c|c|c|c|c|c|}
\hline Dietary fat & $M_{1}$ & $M_{2}$ & $M_{3}$ & Butter & oil \\
\hline Hydrogenated whale oil (m.p. $\left.40-42^{\circ}\right)$ & 30 & - & 30 & - & - \\
\hline Hydrogenated whale oil (m.p. $\left.30-32^{\circ}\right)$ & - & 75 & - & - & - \\
\hline Coconut oil & 45 & - & - & - & - \\
\hline Rape-seed oil & 25 & 25 & 25 & - & - \\
\hline Cottonseed oil & - & - & 45 & - & - \\
\hline Vitamin A (i.u./g dietary fat) & $36 \cdot 6$ & $36 \cdot 8$ & $36 \cdot 6$ & * & $36 \cdot 0$ \\
\hline Carotene (i.u./g dietary fat) & $4 \cdot 2$ & 4.2 & 4.2 & * & 4.0 \\
\hline Vitamin D (i.u./g dietary fat) & $\mathrm{r} \cdot 8$ & 1.8 & $1 \cdot 8$ & * & $x \cdot 8$ \\
\hline \multicolumn{6}{|l|}{ Polyenoic fatty acidst ( $\mathrm{g} /$ roo $\mathrm{g}$ fat $)$} \\
\hline Dienoic: $\ddagger$ & $7 \cdot 5$ & $4 \cdot 9$ & $19^{\circ} 0$ & $2 \cdot 3$ & $24 \cdot 5$ \\
\hline & $4 \cdot 6$ & $2 \cdot 8$ & $23 \cdot 2$ & $2 \cdot 2$ & $20 \cdot 6$ \\
\hline Trienoic: $\ddagger$ & $3 \cdot 2$ & $2 \cdot 0$ & $2 \cdot 9$ & 0.7 & $I \cdot I$ \\
\hline$\S$ & $2 \cdot 6$ & $2 \cdot 1$ & $2 \cdot 7$ & 0.6 & 0.5 \\
\hline Tetraenoic: $\ddagger$ & 0.0 & 0.0 & 0.0 & 0.3 & $0 . \mathrm{I}$ \\
\hline & 0.0 & 0.0 & 0.0 & 0.3 & 0.1 \\
\hline Pentaenoic: $\ddagger$ & 0.0 & 0.0 & 0.0 & 0.2 & 0.0 \\
\hline & 0.0 & 0.0 & 0.0 & 0.2 & 0.0 \\
\hline Hexaenoic: $\ddagger$ & 0.2 & 0.0 & 0.1 & 0.2 & 0.0 \\
\hline & $0 \cdot I$ & 0.2 & 0.0 & 0.0 & 0.0 \\
\hline Iodine value $\left(W_{i j s}\right) \ddagger$ & 52 & 75 & 76 & $3 \mathrm{I}$ & 94 \\
\hline & 49 & 69 & 90 & $3 \mathbf{I}$ & 89 \\
\hline
\end{tabular}

* Not estimated in the samples used in this experiment, in which summer butter was used during the first 26 weeks and winter butter during the last 16 weeks. The vitamin content has previously been found to be: in summer butterfat, vitamin A $33.3 \mathrm{i}$.u./g and carotene 8.4 i.u./g, in winter butterfat, vitamin A I5. I i.u./g and carotene I. 6 i.u./g. Vitamin D was not estimated.

+ Estimated by the alkali-isomerization procedure as described by Hammond \& Lundberg (1953). Figures obtained by this method on hydrogenated fat may be used for guidance and comparison, but the validity of the absolute values remains to be established.

$\ddagger$ Values in samples used during the first 26 weeks of experiment (see p. 355).

$\S$ Values in samples used during the last 16 weeks of experiment (see p. 355).

the height of lesions protruding into the lumen was taken into account in assessing the final grade. Liver specimens were fixed in $10 \%$ formalin (corresponding to $4 \%(\mathrm{w} / \mathrm{v})$ formaldehyde). Paraffin sections were stained routinely with haematoxylin and eosin, and for connective tissue with van Gieson's stain.

\section{RESULTS}

Mean values for serum cholesterol determined over 40 weeks at intervals of 5 weeks, for serum lipoproteins determined at 20 weeks and for body-weights at the outset and at the end of 40 weeks' feeding period, as well as for calorie consumption, are presented in Table 3. It will be seen that the serum-cholesterol content increased on all diets, but by far the greatest increase occurred in the rabbits fed on butter (group I64). Of 
Vol. 14

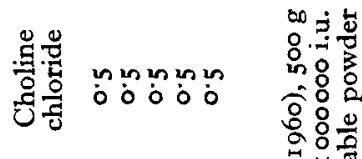

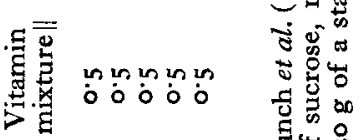

垔安

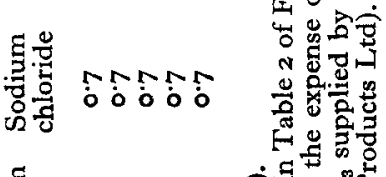

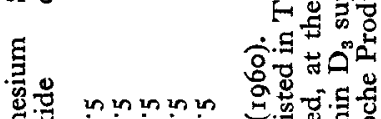

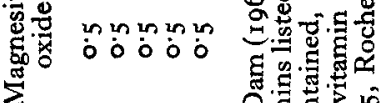

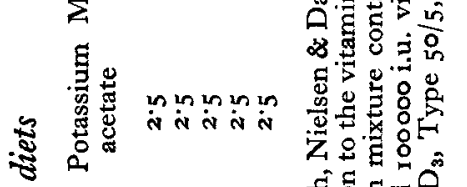

के

舟

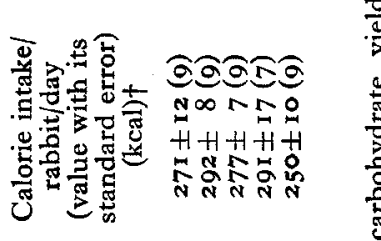

蛋

놀

政

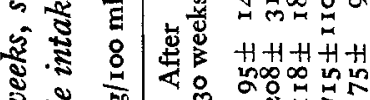

उ.ะ क्ष

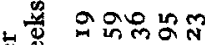

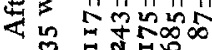

웡

.

递的牙㖞

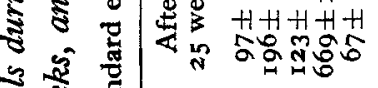

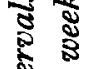

른 웅

-

รี. ․ำ

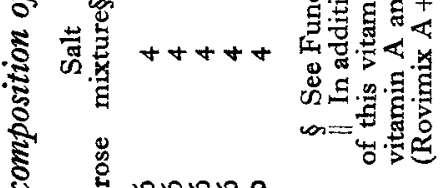

范

离

范

एँ

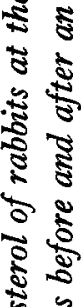

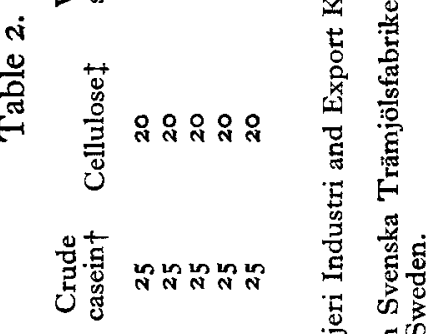

究

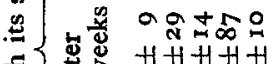

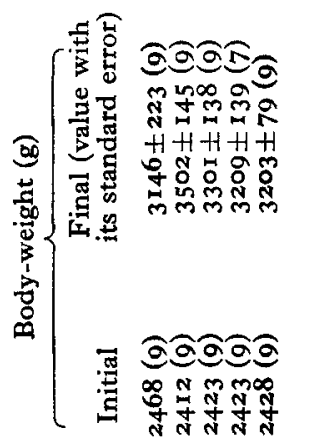

캐

횽

ระ๊

* 胥.

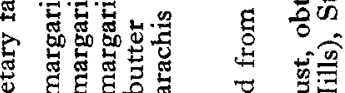

范

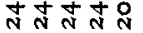

计 등

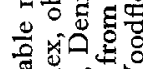

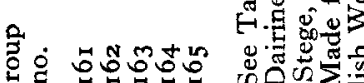

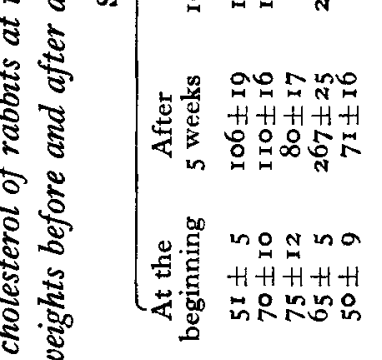

हิ ปี

टे.

胥

है \$

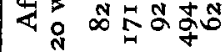

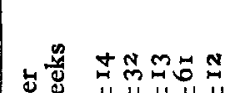

跔

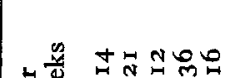

焉 $H+H+H$

इะก

* ํㅗำ

要

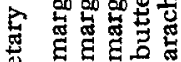

ä 90.0920\%

तो

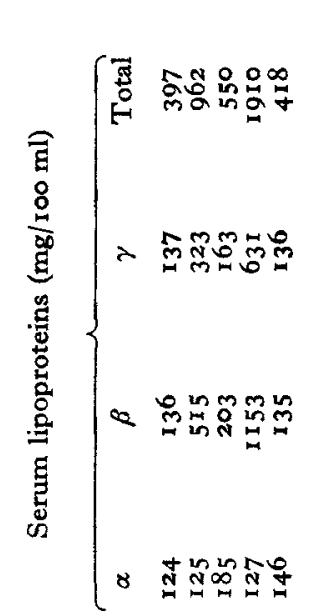

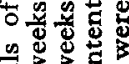

B 3

coso

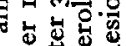

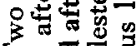

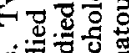

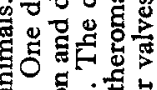

要

4t

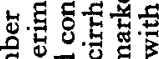

इसे

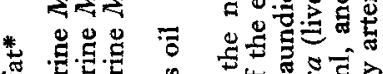

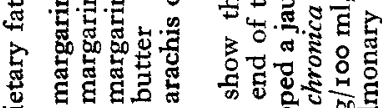

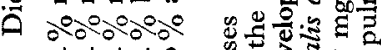

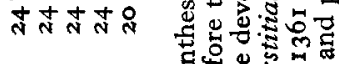

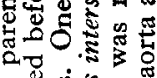

E.

$\dot{m} \approx$

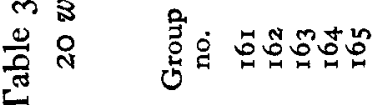

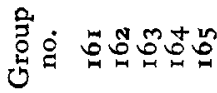

so

证然 
the seven animals in this group alive after a 40 -week feeding period, six had serumcholesterol values ranging between $67 \mathrm{I}$ and $980 \mathrm{mg} / \mathrm{I} 00 \mathrm{ml}$, though one (rabbit no. 34) had a value of only $214 \mathrm{mg} / 100 \mathrm{ml}$. During the whole experimental period this rabbit appeared resistant to the development of hypercholesterolaemia, since its serumcholesterol values never exceeded $306 \mathrm{mg} / 100 \mathrm{ml}$. The rabbits fed on margarine $M_{2}$ (group I62) developed significantly higher serum-cholesterol values than those fed on margarine $M_{1}$ or $M_{3}$ or on arachis oil (groups I6I, 163, 165). The serum-cholesterol values of the rabbits fed on $M_{1}$ or $M_{3}$ did not at any time differ significantly. The arachis-oil diet produced the lowest serum-cholesterol values throughout.

From Table 3 it will be seen that there was no correlation between serum-cholesterol and $\alpha$-lipoprotein values, since the $\alpha$-lipoprotein showed no appreciable changes, whatever the type of dietary fat. However, a close correlation existed between the values for serum cholesterol and those for $\beta$-lipoproteins.

Table 4. Mean intensities of atheromatous lesions in rabbits in aorta and pulmonary artery with their valves after 42 weeks

\begin{tabular}{|c|c|c|c|c|c|c|}
\hline \multirow[b]{3}{*}{$\begin{array}{l}\text { Group } \\
\text { no.* }\end{array}$} & \multirow[b]{3}{*}{ Dietary fat $\dagger$} & \multicolumn{5}{|c|}{ Mean terminal grading $f$} \\
\hline & & \multicolumn{2}{|c|}{ Aorta } & \multirow[b]{2}{*}{$\begin{array}{l}\text { Pulmonary } \\
\text { artery }\end{array}$} & \multicolumn{2}{|c|}{ Valves of } \\
\hline & & Thoracic & Abdominal & & Aorta & $\begin{array}{l}\text { Pulmonary } \\
\text { artery }\end{array}$ \\
\hline $\begin{array}{l}\text { I6I I (9) } \\
\text { I62 (9) } \\
\text { I63 (9) } \\
\text { I64 (7)\$ } \\
\text { I65 (9) }\end{array}$ & $\begin{array}{l}24 \% \text { margarine } M_{1} \\
24 \% \text { margarine } M_{2} \\
24 \% \text { margarine } M_{3} \\
24 \% \text { butter } \\
20 \% \text { arachis oil }\end{array}$ & $\begin{array}{l}0 \\
0 \cdot 4 \\
0 \\
2 \cdot 7 \\
0\end{array}$ & $\begin{array}{l}0 \\
0 \\
0 \\
1 \cdot I \\
0\end{array}$ & $\begin{array}{l}0 \\
0 \\
0 \\
2 \cdot 4 \\
0\end{array}$ & $\begin{array}{l}0 \\
0 \cdot 2 \\
0 \\
1 \cdot 5 \\
0\end{array}$ & $\begin{array}{l}\circ \\
0 \\
\circ \\
\circ \\
0\end{array}$ \\
\hline
\end{tabular}

All animals gained weight during the experiment, and the mean weights and calorie consumption of the groups after a feeding period of 40 weeks did not differ significantly, except for a significantly higher calorie intake by the rabbits fed on margarine $M_{2}$ than by those fed on arachis oil.

A summary of the grading of atheromatous lesions in aorta, pulmonary artery and their valves is provided in Table 4. Marked atherosclerosis was correlated with the degree of hypercholesterolaemia in the rabbits fed on butter. Thus, with the exception of rabbit no. 34, which did not develop hypercholesterolaemia, all rabbits fed on butter had marked atheromatous lesions in the aortas and pulmonary arteries. In the aorta the lesions were almost exclusively located in the thoracic part with a preference for the arcus aortae and the site of origin of an intercostal artery (Pl. I). The aortic valves were also affected. No atheromatous lesions were found on the valves or the first $0.5 \mathrm{~cm}$ of the pulmonary artery. The intermediate serum-cholesterol values of the rabbits fed on margarine $M_{2}$ (cf. Table 3 ) were associated with the appearance of some 
atheromatous lesions in about half of the rabbits. None of the rabbits fed on margarines $M_{1}$ or $M_{3}$ or on arachis oil had visible gross lesions.

The livers of the rabbits receiving butter had a pale yellowish-tan appearance, indicating infiltration of lipid, but the livers of the rabbits fed on the other fats appeared normal. The livers of two out of seven rabbits fed on butter were grossly indurated, and the infiltration of connective tissue was verified by histological examination of sections stained with van Gieson's stain.

\section{DISCUSSION}

In accordance with the experiences of Lambert, Miller, Olsen \& Frost (1958), of Malmros \& Wigand (1959) and of Wigand (1959), we have found that serum cholesterol and development of atheromatous lesions in rabbits fed on purified diets without added cholesterol can be influenced by the type of dietary fat. After 40 weeks on the butter diet the serum-cholesterol level was I I times as high as initially, and 3,4.5,2.5 and 2 times on the diets containing margarines $M_{1}, M_{2}, M_{3}$ and arachis oil, respectively. These differences were accounted for by the $\beta$-lipoproteins, the $\alpha$-fractions showing no significant differences. The high serum-cholesterol values of rabbits fed on butter were associated with marked atheromatous lesions in the aortas and pulmonary arteries. No atherosclerosis was found in the rabbits fed on the diet with arachis oil or with margarine $M_{1}$ or $M_{3}$. In the rabbits fed on the diet with $M_{2}$ (containing a relatively high amount of hydrogenated fat), slight atheromatous lesions were found in some rabbits. The replacement of coconut oil in $M_{1}$ by cottonseed oil in $M_{3}$ did not have any appreciable effect.

The dietary fats used in this experiment differed not only in the nature of the fatty acids, but also in the amount and nature of the sterols contained in the fats. The factors besides the linoleic-acid content, or the combinations of factors, in the fats responsible for the different effects on serum lipids and atherogenesis in the experiment reported here cannot be detailed on the basis of our present knowledge but remain to be elucidated.

\section{SUMMARY}

I. The purpose of the experiment reported here was to investigate the influence of arachis oil, butter and fat mixtures made into margarine on the levels of serum cholesterol and lipoproteins and on the development of atherosclerosis in male rabbits fed ad lib. on purified diets containing $20 \%$ fat without added cholesterol. The rabbits, 6 months old, were distributed over five groups of nine animals each. Serumcholesterol concentrations were measured every 5 weeks over a period of 40 weeks, and lipoproteins were estimated by paper electrophoresis after 20 weeks. The anatomical results were observed grossly on aortas and pulmonary arteries with their valves after a feeding period of 42 weeks.

2. The butter diet induced hypercholesterolaemia, hyper- $\beta$-lipoproteinaemia and a marked development of atheromatous lesions in six out of seven rabbits alive at the end of the experiment. A grossly fatty liver developed in all the rabbits fed on butter, and some of the livers were cirrhotic. The rabbits fed on margarines $M_{1}$ or $M_{3}$ or on 
arachis oil had a relatively low content of cholesterol and $\beta$-lipoprotein in the serum and developed no atherosclerosis. The intermediate serum-lipid values of the rabbits fed on margarine $M_{2}$ were associated with slight atheromatous lesions in some of the rabbits.

\section{REFERENCES}

Funch, J. P., Nielsen, E. \& Dam, H. (1960). Brit. F. Nutr. 14, 1.

Hammond, E. G. \& Lundberg, W. O. (1953). F. Amer. Oil Chem. Soc. 30, 433.

Herrmann, R. G. (1957). Proc. Soc. exp. Biol., N.Y., 94, $5 \circ 3$.

Lambert, G. F., Miller, J. P., Olsen, R. T. \& Frost, D. V. (1958). Proc. Soc. exp. Biol., N. Y., 97, 544. Malmros, H. \& Wigand, G. (1959). Lancet, ii, 749.

McMillan, G. C., Horlick, L. \& Duff, G. L. (1955). Arch. Path. (Lab. Med.), 59, 285.

Swahn, B. (1953). Scand. F. clin. Lab. Invest. 5, Suppl. 9.

Wigand, G. (1959). Acta med. scand. r66, Suppl. 35 r.

\section{EXPLANATION OF PLATE \\ Plate I}

Thoracic aorta from a rabbit fed on diet with $24 \%$ butter for 39 weeks. The sites of predilection for atheromatous lesions will be noticed. The severity of the lesions was assessed as grade 2 (see p. 356 ). 


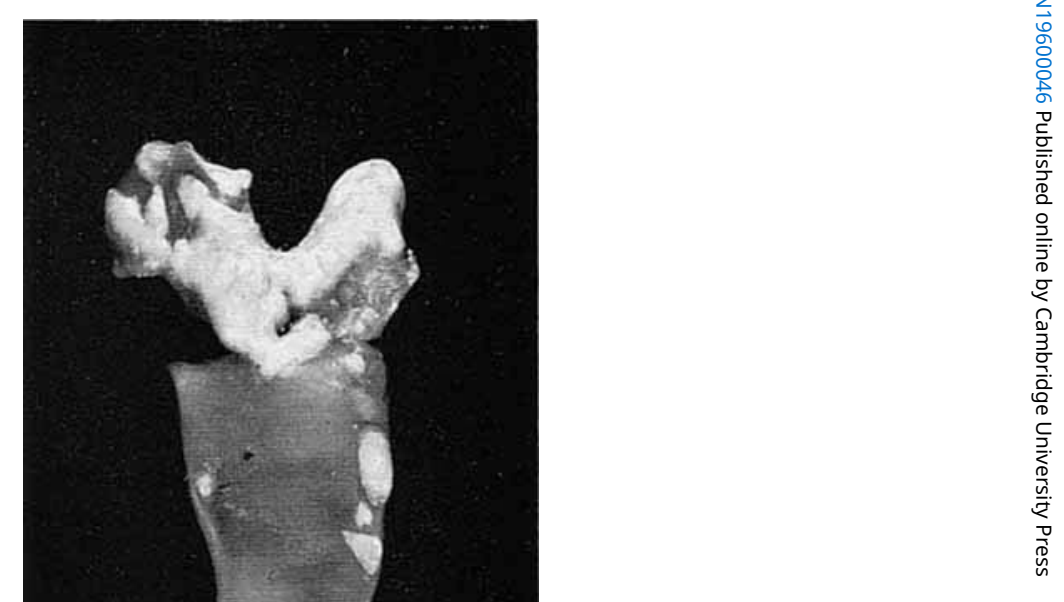

